\title{
PERAN FAKTOR PENYEKALA PADA KONSTRUKSI INTERPOLASI FRAKTAL
}

\author{
$\operatorname{Marwan}^{1}$ \\ ${ }^{1}$ Program Studi Matematika FMIPA Universitas Mataram, Mataram \\ Email:marwanmath@yahoo.co.id
}

Abstrak : Telah diketahui bahwa suatu fungsi fraktal $f:\left[x_{0}, x_{N}\right] \rightarrow \mathbb{E}$ yang menginterpolasi data $\left\{\left(x_{i}, F_{i}\right) \in \mathbb{R}^{2} \mid i=0,1,2, \ldots, N\right\}$ sedemikian hingga $f\left(x_{i}\right)=F_{1}$ untuk $i=0,1,2, \ldots, N$ dapat dikonstruksi dari suatu Sistem Fungsi Iterasi (SFI) berdasarkan teorema titik tetap pada pemetaan kontraktif. Dengan mengambil suatu bentuk pemetaan Affine, yang merupakan salah satu bentuk pemetaan kontraktif untuk SFI, dapat dibuktikan eksistensi atraktor SFI dimaksud yang tidak lain merupakan interpolan fraktal dari data terkait. Faktor penyekala $d_{n}$ yang termuat di dalam pemetaan affine memegang peran sebagai syarat perlu eksistensi dan ketunggalan fungsi interpolasi fraktal suatu data. Syarat perlu tersebut berlaku pada batasan nilai $O \beta\left|d_{n}\right|<1$.

Kata kunci: interpolan fraktal, SFI, teorema titik tetap, pemetaan affine, faktor penyekala.

Abstract : It is known that a fractal functions $f:\left[x_{0}, x_{N}\right] \rightarrow \mathbb{E}$ that interpolated the data $\left\{\left(x_{i}, F_{i}\right) \in \mathbb{R}^{2} \mid i=0,1,2, \ldots, N\right\}$ such that $f\left(x_{i}\right)=F_{1}, i=0,1,2, \ldots, N$ can be constructed from an Iterated Function System (IFS) based on The Fixed Point Theorem on contractive mappings. By taking a certain Affine Mapping, which is a form of contractive mapping on IFS, the existence of IFS' attractor can be proven as the fractal interpolan of related data. The vertical scaling factor $d_{n}$ contained in the affine mapping role as a necessary condition of existence and uniqueness of a fractal interpolation function data. The necessary condition of is on the interval.

Keywords : fractal interpolan, IFS, The Fixed Point Theorem, Affine Mapping, vertical scaling factor)

\section{PENDAHULUAN}

Analisis data menggunakan pendekatan fungsi yang tidak mulus (irregular) dewasa ini semakin diminati para peneliti. Obyek-obyek alam seperti gunung, garis pantai hingga pola geometris suatu galaksi ternyata tidak dapat digambarkan dengan baik menggunakan geometri euklides. Pola geometris lainnya seperti signal suara, signal gempa dan fluktuasi inflasi juga mengisyaratkan penggunaan pendekatan fungsi yang tidak mulus untuk merepresentasikannya. Geometri fraktal menyediakan kerangka umum untuk mempelajari himpunan yang tidak teratur (irregular sets).
Secara umum dikenal dua kelompok metode interpolasi di dalam menentukan fungsi representasi dari suatu data yang dipunyai, yaitu : Interpolasi dengan fungsi mulus (terdiferensial) dan Interpolasi dengan fungsi fraktal (umumnya tak terdiferensial). Gambaran umum tentang perbedaan mendasar kedua metode di atas di dalam menganalisis data diperlihatkan pada gambar 1. 


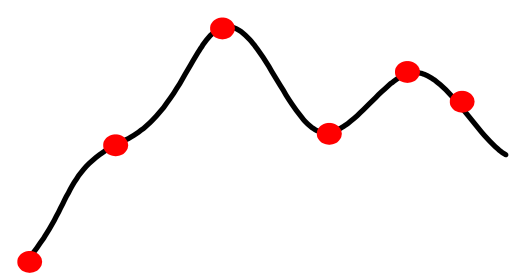

(a)

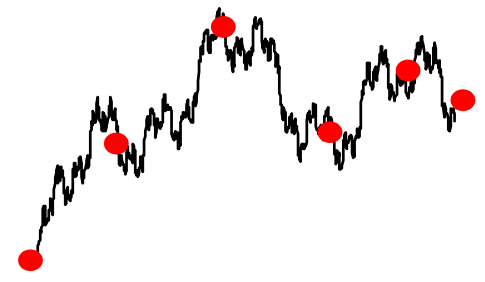

(b)

Gambar 1 : Perbandingan interpolasi fungsi mulus (a) dengan interpolasi fraktal (b)

Pemilihan metode yang tepat untuk menganalisis data dipengaruhi beberapa hal, antara lain : karakteristik data, banyaknya data, kemampuan numerical tools dalam menganalisis data serta kemampuan graphical tools dalam merepresentasi data. Karakteristik suatu data sangat mempengaruhi keputusan pemilihan interpolasi fraktal atau bukan. Jika suatu data adalah representasi dari obyek 'kasar' atau peristiwa 'unpredictable', maka interpolasi fraktal akan lebih berperan, sebab fungsi interpolan yang dihasilkan oleh metode ini bersifat tak terdiferensial (tapi tetap kontinu), berdimensi tak bulat, dan pada tingkat tertentu bersifat serupa-diri (self-similar).

Diduga kuat data curah hujan memiliki karakterisitik serupa-diri. Jika demikian, maka representasi time seiesnya dapat diinterpolasi dengan metode fraktal. Sebagai konsekuensi logisnya adalah kemungkinan mendapatkan kembali data yang hilang dalam interval waktu tertentu, bahkan prediksi data di waktu yang akan datang.

Penelitian ini mencoba menganalisis data curah hujan dengan pendekatan interpolasi fraktal. Sampel data curah hujan diambil dari data sekunder pada hasil penelitian [1].

Meskipun tidak diuraikan secara detail, teori interpolasi fraktal telah diisyaratkan oleh [2] dengan baik. Landasan teori untuk interpolasi jenis ini, yang menggunakan Sistem Fungsi Iterasi (SFI) sebagai generatornya dijelaskan cukup detail oleh [3], serta [4], sedangkan [5] telah membuktikan eksistensi interpolasi fraktal untuk suatu data.

Di bidang pencitraan digital, [4] memberikan metode rescaling suatu citra dengan memanfaatkan interpolasi fraktal fungsi satu dan dua peubah. Pemodelan fungsi interpolasi fraktal dari data traffic flow, [6] dengan landasan metode hasil riset [7] telah memberikan hasil inspiratif untuk mencoba menggunakan pola yang serupa pada data curah hujan. Dengan memperhatikan pola timeseries data curah hujan oleh [1], akan ditinjau model interpolasi fraktal dengan faktor penyekala vertikal yang berbeda-beda.

\section{TEORI DASAR}

Pembicaraan interpolasi fraktal didasari oleh uraian tentang ruang fraktal yang merupakan suatu ruang metrik lengkap. Fungsi interpolan yang akan digunakan untuk menginterpolasi suatu data pada dasarnya adalah suatu titik tetap dari suatu atau sekoleksi transformasi. Titik tetap itulah yang lalu disebut atraktor di dalam ruang fraktal.

\section{Definisi 1 (Ruang Fraktal)}

Diketahui $(X, d)$ ruang metrik lengkap dan $\mathscr{H}(X)=\{A \mid A \subset X, A$ kompak dan $A \neq \emptyset\}$

Metrik Hausdorff adalah suatu fungsi $h: \mathcal{H}(X) \times \mathcal{H}(X) \rightarrow \mathbb{E}$, dengan definisi :

$h(A, B)=\operatorname{maks}\{d(A, B), d(B, A)\}$

di mana

$$
\begin{aligned}
& d(A, B)=\operatorname{maks}\{d(x, B) \mid x \in A\}, \forall A, B \in \mathcal{H}(X) \\
& \qquad d(x, B)=\min \{d(x, y) \mid y \in B\}, \forall x \in X \operatorname{dan} B \in \mathcal{H}(X) \\
& \text { Himpunan }(\mathcal{H}(X), h(d)) \text { dinamakan ruang } \\
& \text { fraktal dan anggotanya disebut fraktal atau } \\
& \text { atraktor. }
\end{aligned}
$$

\section{Definisi 2 (titik tetap)}

Diketahui $\mathrm{f}: \mathrm{X} \longrightarrow \mathrm{X}$ suatu transformasi pada ruang metrik $X$. Titik $x_{f} \in X$ sedemikian hingga $f\left(x_{f}\right)=x_{f}$ disebut titik tetap transformasi $f$.

Definisi 3 (pemetaan kontraktif) 
$\mathrm{f}: \mathrm{X} \longrightarrow \mathrm{X}$ suatu pemetaan (transformasi) pada ruang metrik $(\mathrm{X}, \mathrm{d})$ dikatakan kontraktif jika ada bilangan real s, $0 \mathrm{bs}<1$, sedemikian hingga $d(f(x), f(y)) \leq s \cdot d(x, y), \forall x, y \in X$.

Bilangan $\mathrm{s}$ disebut faktor kontraktivitas pemetaan $f$.

\section{Definisi 4 (Sistem Fungsi Iterasi)}

SFI (Sistem Fungsi Iterasi) adalah suatu sistem yang terdiri dari suatu ruang metrik lengkap $(\mathrm{X}, \mathrm{d})$ dan pemetaan kontraksi $\mathrm{w}_{\mathrm{n}}: \mathrm{X} \longrightarrow \mathrm{X}$ dengan faktor kontraksi $s_{n}, n=1,2,3, \ldots, N$. dinotasikan $\left\{\mathrm{X} ; \mathrm{w}_{\mathrm{n}}, \mathrm{n}=1,2,3, \ldots, \mathrm{N}\right\}$ dengan faktor kontraktivitas $\mathrm{s}=\operatorname{maks}\left\{\mathrm{s}_{1}, \mathrm{~s}_{2}, \ldots, \mathrm{s}_{\mathrm{N}}\right\}$.

Teorema berikut menyatakan eksistensi titik tetap suatu pemetaan kontraktif.

\section{Teorema 1 (teorema titik tetap)}

Jika $: \mathrm{X} \longrightarrow \mathrm{X}$ kontraktif, maka terdapat dengan tunggal titik tetap $\mathrm{x}_{\mathrm{f}} \in \mathrm{X}$, yaitu $\mathrm{f}\left(\mathrm{x}_{\mathrm{f}}\right)=\mathrm{x}_{\mathrm{f}}$ sedemikian hingga $\lim _{n \rightarrow \infty} f^{n}(x)=x_{f}, \forall x \in X$

\section{Teorema 2 (eksistensi atraktor SFI kontraktif)} Jika $\left\{\mathbb{R}^{2} \mid w_{k}, k=1,2, \ldots n\right\}$ suatu SFI dengan faktor kontraktivitas $\mathrm{s}_{\mathrm{k}}$, maka pemetaan

$W: \mathcal{H}\left(\mathbb{R}^{2}\right) \rightarrow \mathcal{H}\left(\mathbb{R}^{2}\right)$

dengan definisi

$W(B)=\cup_{k=1}^{n} w_{k}(B), \forall B \in \mathcal{H}\left(\mathbb{R}^{2}\right)$, merupakan suatu pemetaan kontraktif pada ruang fraktal $\left(\mathscr{H}\left(\mathbb{R}^{2}\right), h\right)$ dengan faktor kontraktivitas

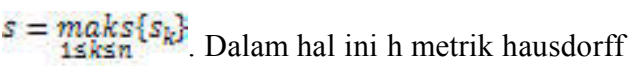
yang dibangun atas metrik euclid pada bidang $\mathbb{R}^{2}$. Titik tetapnya yang tunggal (berdasarkan Teorema 1) adalah A yang memenuhi $A=W(A)$ dan ditentukan oleh

$A=\lim _{n \rightarrow \infty} w_{k}(B), \forall B \in \mathfrak{H}\left(\mathbb{R}^{2}\right)$

Selanjutnya A dinamakan Atraktor SFI tersebut.

Bukti : (lihat [8])

\section{HASIL DAN PEMBAHASAN}

Konstruksi fungsi interpolasi fraktal pada penelitian ini dilakukan dengan menggunakan SFI yang semua pemetaan di dalamnya merupakan pemetaan/ transformasi Afin bentuk khusus.

\section{Definisi 5 (Transformasi Afin)}

Suatu transformasi $\mathrm{S}: \mathbb{R}^{2} \rightarrow \mathbb{R}^{2}$ dengan $\mathrm{S}(\mathrm{x})=\mathrm{T}(\mathrm{x})+\mathrm{p}, \mathrm{T}$ suatu transformasi linear nonsingular dan $\mathrm{p}$ suatu titik di disebut Transformasi Afin atau Afinitas.

Afinitas merupakan suatu transformasi yang efek kontraksi maupun ekspansinya ke setiap arah tidak perlu sama. Mengingat trasnformasi linear selalu dapat dinyatakan dengan suatu matriks, maka afinitas pada dapat dirumuskan sebagai berikut:

$$
S(x)=A x+p \Leftrightarrow S\left(\begin{array}{l}
x_{1} \\
x_{2}
\end{array}\right)=\left(\begin{array}{ll}
a & b \\
c & d
\end{array}\right)\left(\begin{array}{l}
x_{1} \\
x_{2}
\end{array}\right)+\left(\begin{array}{l}
e \\
f
\end{array}\right)
$$

dan merupakan suatu rotasi atau refleksi yang disusul oleh dilatasi dan translasi.

\section{Definisi 6 (Fungsi Interpolasi)}

Fungsi interpolasi suatu data $\left\{\left(x_{i}, F_{i}\right) \in \mathbb{R}^{2} \mid i=0,1,2, \ldots, N\right\}$

$x_{0}<x_{1}<x_{2}<\ldots<x_{N}$ didefinisikan sebagai suatu fungsi kontinu $f:\left[x_{0}, x_{N}\right] \rightarrow \mathbb{E}$, sedemikian hingga $f\left(x_{i}\right)=F_{\text {i untuk }} i=0,1,2, \ldots, N$.

\section{Definisi 7 (Fungsi Interpolasi Fraktal)}

Fungsi interpolasi fraktal suatu data $\left\{\left(x_{i}, F_{\mathrm{i}}\right) \in \mathbb{R}^{2} \mid i=0,1,2, \ldots, N\right\}$

$x_{0}<x_{1}<x_{2}<\ldots<x_{N}$ didefinisikan sebagai suatu fungsi interpolasi $f:\left[x_{0}, x_{N}\right] \rightarrow \mathbb{E}$, yang grafiknya merupakan atraktor dari suatu SFI.

Untuk mendapatkan fungsi interpolasi yang merupakan atraktor dari suatu SFI seperti yang dinyatakan di dalam definisi 7 , dipilih SFI $\left\{\mathbb{R}^{2}: w_{n}, n=1,2, \ldots, N\right\}$ 
dengan $W_{n}$ suatu transformasi affine bentuk khusus, yaitu

$$
\begin{aligned}
: \quad & w_{n}\left(\begin{array}{l}
x \\
y
\end{array}\right)=\left(\begin{array}{ll}
a_{n} & 0 \\
c_{n} & d_{n}
\end{array}\right)\left(\begin{array}{l}
x \\
y
\end{array}\right)+\left(\begin{array}{l}
e_{n} \\
f_{n}
\end{array}\right) \\
& \text { yang dibatasi oleh } \\
& w_{n}\left(\begin{array}{l}
x_{0} \\
F_{0}
\end{array}\right)=\left(\begin{array}{l}
x_{n-1} \\
F_{n-1}
\end{array}\right) \text { dan } w_{n}\left(\begin{array}{l}
x_{N} \\
F_{N}
\end{array}\right)=\left(\begin{array}{l}
x_{n} \\
F_{n}
\end{array}\right) \\
& \text { untuk } n=1,2, \ldots, N .
\end{aligned}
$$$$
\text { Dari (2) dan (3) diperoleh }
$$$$
a_{n} x_{0}+e_{n}=x_{n-1}
$$$$
a_{n} x_{N}+e_{n}=x_{n}
$$$$
c_{n} x_{0}+d_{n} F_{0}+f_{n}=F_{n-1}
$$$$
c_{n} x_{N}+d_{n} F_{N}+f_{n}=F_{n}
$$

untuk $n=1,2, \ldots, N$.

Selanjutnya dari (4) dan (5) dipeoleh

$$
\begin{aligned}
& a_{n}=\frac{x_{n}-x_{n-1}}{x_{N}-x_{0}} \\
& e_{n}=\frac{x_{N} x_{n-1}-x_{0} x_{n}}{x_{N}-x_{0}}
\end{aligned}
$$

untuk $n=1,2, \ldots, N$.

Akhirnya, dari (6) dan (7) dengan mengambil $d_{\text {rn sebagai }}$ variabel bebas yang disebut faktor penyekala vertikal, diperoleh

$$
\begin{aligned}
& c_{n}=\frac{F_{n}-F_{n-1}}{x_{N}-x_{0}}-d_{n} \frac{F_{N}-F_{0}}{x_{N}-x_{0}} \\
& f_{n}=\frac{x_{N} F_{n-1}-x_{0} F_{n}}{x_{N}-x_{0}}-d_{n} \frac{x_{N} F_{0}-x_{0} F_{N}}{x_{N}-x_{0}}
\end{aligned}
$$

עengan Kontsruksı pemetaan anggota SHI seperti di atas, selanjutnya diperlukan jaminan eksistensi titik tetap (atraktor) dari SFI tersebut. Teorema berikut menyatakan jaminan dimaksud.

\section{Teorema 3}

Diketahui sebuah bilangan asli $\mathrm{N}>1$ dan SFI $\left\{\mathbb{R}^{2}: w_{n}, n=1,2, \ldots, N\right\} \quad$ yang telah dikonstruksikan pada (2) dan (3) yang berkaitan dengan data $\left\{\left(x_{n}, F_{n}\right) \in \mathbb{R}^{2} \mid n=0,1,2, \ldots, N\right\}$. Jika faktor penyekala vertikal $d_{n}$ memenuhi $O \beta\left|d_{n}\right|<1$ untuk $n=1,2, \ldots, N$., maka terdapat suatu metrik d pada $\mathbb{R}^{2}$ yang ekuivalen dengan metrik euklides sehingga SFI-nya hiperbolik terhadap metrik d. Khususnya terdapat dengan tunggal suatu atraktor $\mathrm{G}$ dalam yang memenuhi :

$$
G=\bigcup_{n=1}^{N} w_{n}(G)
$$

Bukti :

Didefinisikam suatu metrik $d$ pada $\mathbb{R}^{2}$ :

$d\left(\left(x_{1}, y_{1}\right),\left(x_{2}, y_{2}\right)\right)=\left|x_{1}-x_{2}\right|+\theta\left|y_{1}-y_{2}\right|$.

q suatu bilangan positif yang akan ditentukan kemudian.

Dengan definisi tersebut, $\mathrm{d}$ akan ekuivalen dengan metric euklides.

Ambil sebanrang $\mathrm{n} \in\{1,2, \ldots, N\}$ dan dibentuk $a_{n}, c_{n}, e_{n}, f_{n}$ seperti pada (8) - (11), diperoleh

$d\left(w_{n}\left(x_{1}, y_{1}\right), w_{n}\left(x_{2}, y_{2}\right)\right)=d\left(\left(a_{n} x_{1}+e_{n}, c_{n} x_{1}+d_{n} y_{1}+f_{n}\right),\left(a_{n} x_{2}+e_{n}, c_{n} x_{2}+d_{n} y_{2}+f_{n}\right)\right)$

$=\left|a_{n} x_{1}+e_{n}-\left(a_{n} x_{2}+e_{n}\right)\right|+\theta \mid c_{n} x_{1}+d_{n} y_{1}+f_{n}-\left(c_{n} x_{2}+d_{n} y_{2}+f_{n} \mid\right.$

$=a_{n}\left|x_{1}-x_{2}\right|+\theta\left|c_{n}\left(x_{1}-x_{2}\right)+d_{n}\left(y_{1}-y_{2}\right)\right|$

$\leq\left|a_{n}\right|\left|x_{1}-x_{2}\right|+\theta\left|c_{n}\left(x_{1}-x_{2}\right)\right|+\theta\left|d_{n}\left(y_{1}-y_{2}\right)\right|$

$=\left|a_{n}\right|\left|x_{1}-x_{2}\right|+\theta\left|c_{n}\left(x_{1}-x_{2}\right)\right|+\theta\left|d_{n}\left(y_{1}-y_{2}\right)\right|$

$=\left(\left|a_{n}\right|+\theta\left|c_{n}\right|\right)\left|x_{1}-x_{2}\right|+\theta\left|d_{n}\right|\left|y_{1}-y_{2}\right|$

Karena $N \geq 2$, diperoleh $\left|a_{n}\right|=\frac{\left|x_{n}-x_{n-1}\right|}{\left|x_{N}-x_{n}\right|}<1$.

Tika $c_{1}=c_{2}=c_{3}=\cdots=c_{n}=0$, dipilih $\theta=1$, sehingga diperoleh

$d\left(w_{n}\left(x_{1}, y_{1}\right), w_{n}\left(x_{2}, y_{2}\right)\right) \leq\left(\left|a_{n}\right|+\theta\left|c_{n}\right|\right)\left|x_{1}-x_{2}\right|+\theta\left|d_{n}\right|\left|\left(y_{1}-y_{2}\right)\right|$

$=\left|a_{n}\right|\left|x_{1}-x_{2}\right|+\left|d_{n}\right|\left|\left(y_{1}-y_{2}\right)\right| \leq \operatorname{sd}\left(\left(x_{1}, y_{1}\right),\left(x_{2}, y_{2}\right)\right)$

dengan $s=$ maks $\left\{\left|a_{n}\right|,\left|d_{n}\right|: n=1,2, \ldots, N\right\}<1$, yaitu $\left\{\mathbb{R}^{2}: w_{n,}, n=1,2, \ldots, N\right\}$ SFI hiperbolik terhadap metrikd.

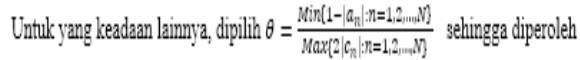

$d\left(w_{n}\left(x_{1}, y_{1}\right), w_{n}\left(x_{2}, y_{2}\right)\right) \leq\left(\left|a_{n}\right|+\theta\left|c_{n}\right|\right)\left|x_{1}-x_{2}\right|+\theta\left|d_{n}\right|\left|\left(y_{1}-y_{2}\right)\right|$

$\leq a\left|x_{1}-x_{2}\right|+\theta \delta\left|y_{1}-y_{2}\right|$

$\leq \operatorname{Maks}\{a, 0\} d\left(\left(x_{1}, y_{1}\right),\left(x_{2}, y_{2}\right)\right)=\operatorname{sd}\left(x_{1}, y_{1}\right),\left(x_{2}, y_{2}\right)$

dengan $a=\left(1 / 2+\frac{\operatorname{Maks}\left(a_{n} \mid: n=1,2, \ldots, N\right)}{2}\right)<1$. Nilaia a ini diperoleh dari:

$\left|a_{n}\right|+\theta\left|c_{n}\right|=\left|a_{n}\right|+\frac{\operatorname{Min}\left\{1-\left|a_{n}\right|: n=1,2, \ldots, N\right\}}{\operatorname{Maks}\left\{2\left|c_{n}\right|: n=1,2, \ldots, N\right\}}\left|c_{n}\right| \leq\left|a_{n}\right|+\frac{\operatorname{Min}\left\{1-\left|a_{n}\right|: n=1,2, \ldots, N\right\}}{2}$

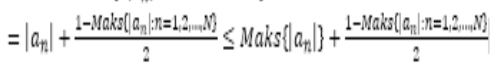

$=1 / 2+\frac{\operatorname{Maks}\left[\operatorname{lan}_{n}: n=1,2, N\right]}{2}$

Dengan demikian dapat dipilih

$\delta=\operatorname{Maks}\left\{\left|d_{n}\right|: n=1,2, \ldots, N\right\}<1$ dan $s=\operatorname{Maks}\{a, \delta\}$

yang berarti $\left\{R^{2}: w_{n}, n=1,2, \ldots, N\right\}$ SFI hiperbolik

terhadap metrik d. menurut Teorema 1 dan Teorema 2,

terdapat dengan tunggal suatu atraktor $G \in \mathscr{H}\left(\mathbb{R}^{2}\right)$. n

Selanjutnya, pada teorema berikut dinyatakan tentang kekontinuan dari fungsi interpolasi fraktal. 


\section{Teorema 4}

Diketahui sebuah bilangan asli $\mathrm{N}>1$ dan SFI $\left\{\mathbb{R}^{2}: w_{n}, n=1,2, \ldots, N\right\} \quad$ yang telah dikonstruksikan pada (2) dan (3) yang berkaitan dengan data $\left\{\left(x_{n}, F_{n}\right) \in \mathbb{R}^{2} \mid n=0,1,2, \ldots, N\right\}$. Jika diberikan faktor penyekala vertikal ${ }^{d_{n}}$, $O \beta\left|d_{n}\right|<1$ untuk $n=1,2, \ldots, N$ sedemikian hingga SFI hiperbolik dan G atraktor dari SFI, maka $\mathrm{G}$ merupakan grafik dari suatu fungsi kontinu $f_{0}:\left[x_{0}, x_{N}\right] \rightarrow \mathbb{E}$ yang menginterpolasi data, ditulis

dengan untuk .

Bukti : (lihat [5]).

Berdasarkan teorema 3 dan teorema 4 di atas, dapat dilihat bahwa faktor penyekala vertikal memegang peranan yang sangat penting. Dari teorema 3 dapat dikatakan bahwa syarat merupakan syarat perlu eksis dan tunggalnya atraktor khususnya pada ruang Euclid, sedangkan di teorema 4 diperjelas lagi bahwa atraktor $\mathrm{G}$ yang dinyatakan sebelumnya merupakan grafik suatu fungsi kontinu yang menginterpolasi data yang diberikan.

Pada penelitian ini digunakan contoh data curah hujan olahan dari Stasiun Lingkok Lime yang berlokasi di daerah aliran sungai Babak, Lombok Barat NTB pada rentang waktu 2000 hingga 2009.
Tabel 1 : Data Curah Hujan Maksimum Harian pada Stasiun

Lingkok Lime Tahun 2000-2009 (diolah dari [1])

\begin{tabular}{|c|c|c|}
\hline Waktu & $(\operatorname{tgl} / \mathrm{bl} / \mathrm{th})$ & $\begin{array}{c}\text { Curah Hujan } \\
(\mathrm{mm})\end{array}$ \\
\hline $15 / 03 / 00$ & & 29 \\
\hline $22 / 03 / 00$ & & 30 \\
\hline $16 / 10 / 00$ & & 150 \\
\hline $25 / 02 / 01$ & & 6 \\
\hline 09/06/01 & & 40 \\
\hline 11/11/01 & & 97 \\
\hline 03/01/02 & & 8 \\
\hline 21/11/02 & & 160 \\
\hline $16 / 12 / 02$ & & 11 \\
\hline 13/10/03 & & 0 \\
\hline 27/10/03 & & 104 \\
\hline $15 / 12 / 03$ & & 10 \\
\hline 29/02/04 & & 20 \\
\hline 28/12/04 & & 102 \\
\hline $22 / 11 / 05$ & & 66 \\
\hline 23/11/05 & & 42 \\
\hline $18 / 12 / 05$ & & 130 \\
\hline $03 / 01 / 96$ & & 0 \\
\hline 03/01/06 & & 146 \\
\hline 04/04/06 & & 12 \\
\hline $04 / 04 / 06$ & & 38 \\
\hline 08/01/07 & & 10 \\
\hline 18/12/07 & & 130 \\
\hline 22/12/07 & & 0 \\
\hline $04 / 11 / 08$ & & 120 \\
\hline 10/01/09 & & 230 \\
\hline 11/01/09 & & 235 \\
\hline
\end{tabular}

Contoh model grafis interpolasi fraktal data pada tabel 1 dikerjakan menggunakan perangkat lunak FreePascal (program dimodifikasi dari [9]) dengan faktor penyekala berbeda-beda diperlihatkan masing-masing pada gambar 2 (a), (b) dan (c).

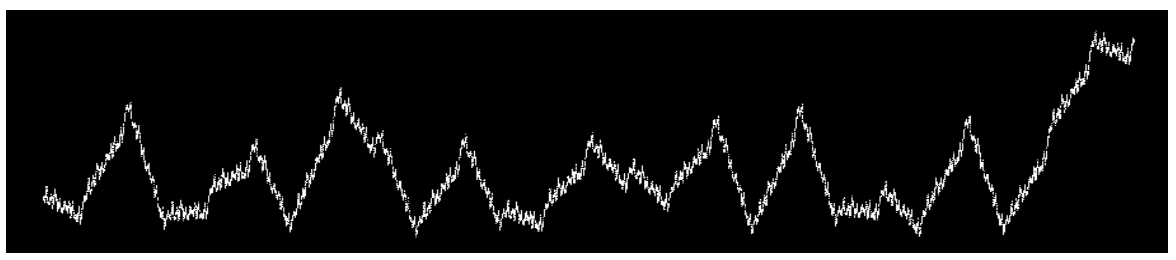

(a)

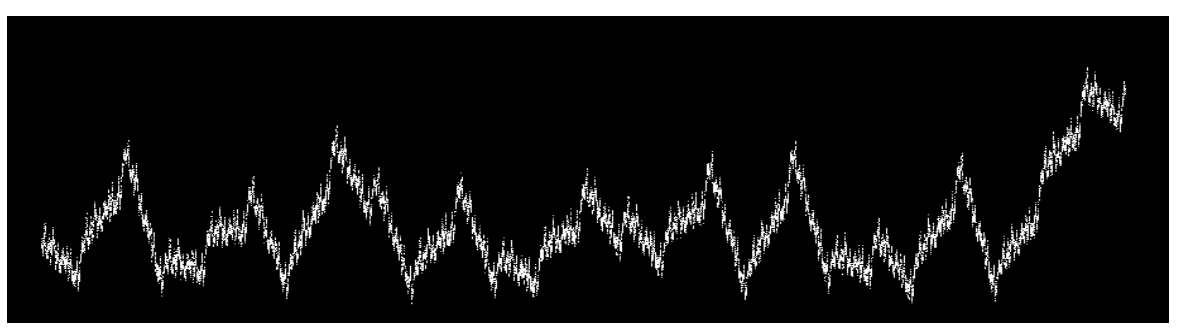

(b) 


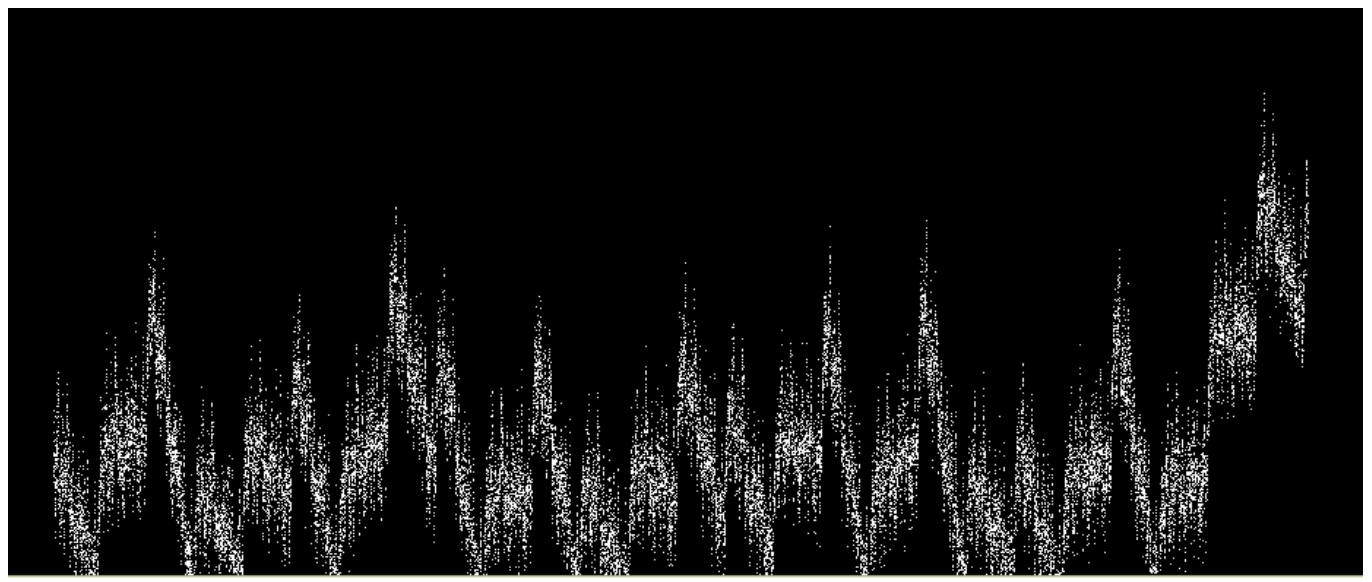

(c)

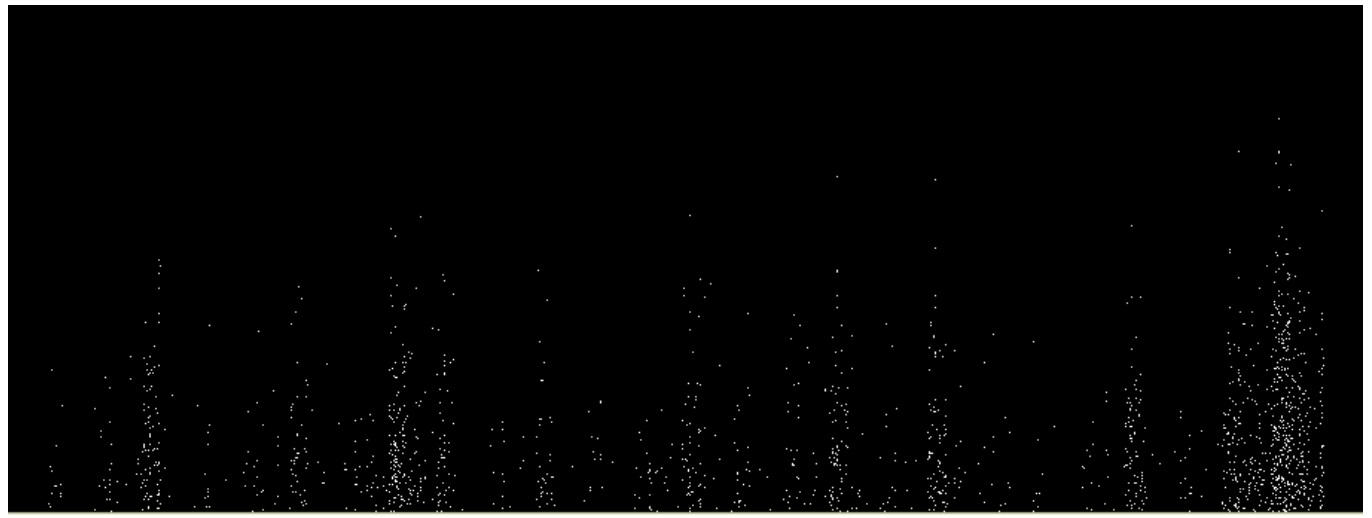

(d)

Gambar 2: $\quad$ Hasil visualisasi interpolasi fraktal data curah hujan dengan faktor penyekala (a) $?_{?}=0,15$, (b) $?_{n}=0,25$, (c) $?_{\eta}=0,50$ dan (d) $?_{\eta}=0,85$

\section{SIMPULAN}

(a) Dengan mengambil suatu pemetaan afin seperti persamaan (2) dengan syarat tambahan seperti dinyatakan teorema 3, maka terjamin eksistensi interpolan fraktal suatu data yaitu atraktor dari SFI yang terkait.

(b) Faktor penyekala $d_{n}, O \beta\left|d_{n}\right|<1$ pada konstruksi interpolasi fraktal menggunakan pemetaan afin pada persamaan (2) merupakan syarat perlu eksistensi dan ketunggalan atraktor khususnya pada ruang euclid. Lebih jauh, atraktor yang dimaksud adalah suatu fungsi kontinu yang dapat digunakan untuk menginterpolasi suatu data.

(c) Visualisasi hasil interpolasi pada data curah hujan menunjukkan bahwa ada perbedaan yang visual fungsi interpolasi pada nilai faktor penyekala berbeda. Jika dn dekat ke nilai 1, visual fungsi interpolasi semakin tidak tampak.

\section{DAFTAR PUSTAKA}

[1] Hadijati M. dan Marwan, 2009, Analisis Curah Hujan dengan Pendekatan Kernel Nonparametrik untuk Membuat Kurva Intensity-Duration-Frequency
(IDF) : Studi Kasus di Kawasan Rawan Banjir Pulau Lombok Nusa Tenggara Barat, Laporan Penelitian Hibah Strategi Nasional Tahun Anggaran 2009, Universitas Mataram

[2] Falconer, K., 1990, Fraktal Geometry: Mathematical Foundations and Applications, John Wiley \& Sons, Chichester.

[3] Kocic Lj.M. and Simoncelli A.C., 2000, Notes on Fraktal Interpolation, NOVI SAD J. Math, 30:3, 59-68

[4] Kobes, R. and Penner, A.J., June 2003, Non-Linear Fraktal Interpolating Functions Of One And Two Variables, http://arXiv:nlin/0306014v1

[5] Widodo, 2003, Sistem fungsi iterasi dan eksistensi interpolasi fraktal, J. Pendidikan Matematika dan Sains : 3,VIII, 129-136.

[6] Xu Y., et al., 2005, Self-Similar Traffic Fraktal-modeling and Its Prediction Methods, J. Information \& Computational Science 2: 1, 169-173. 
J. Pijar MIPA, Vol. VII No.2, September : 86 - 92

[7] Gospodinov M. and Gospodinova E., 2005, The Graphical Methods for Estimating Hurst Parameter of SelfSimilar Network Traffic, International Conference on Computer and Technologies - CompSysTech'2005, p.IIIB 19 1-3

[8] Susanta, B., dkk, 1993, Perkenalan Dengan Geometri Fraktal : Laporan Penelitian, Fakultas Matematika dan Ilmu Pengetahuan Alam Universitas Gadjah Mada, Yogyakarta

[9] Burrahman M, 2011, Konstruksi Interpolasi Fraktal pada Data Pasang Surut Air Laut di Lombok Timur, Skripsi, Program Studi Matematika FMIPA Universitas Mataram, Mataram. 